\title{
Some new hope but still no hype for academic psychiatry in Norway
}

\author{
Molecular Psychiatry (2005) 10, 127-128. \\ doi:10.1038/sj.mp.4001631
}

Norway is ranked among the richest countries in the world, a fact that is closely linked to its role as a major worldwide exporter of oil and gas. The Norwegian population, with its high level of education, is therefore in a fortunate situation, for the time being. Upcoming worries for the post-oil era are based on foresight: Norway is a high-cost country, and the employment in the traditional export industry has markedly decreased at a troublesome rate. Will there be enough knowledge and technology on an internationally competitive level to make a new way of living in the decades to come? The funding of research and development in Norway continues nevertheless to stay rather low, whereas the income of petroleum export is at large invested abroad, despite a long-term national political goal to increase the funding of research to reach the average of the OECD countries by the end of 2005. This deadline is now coming up quickly, but in real life, the total amount of money spent in this area in Norway is still low, estimated to about $1.6 \%$ of gross national product (GNP) as compared to an average of $2.3 \%$ for the OECD countries. ${ }^{1}$ The reason for bringing up this background picture is that psychiatry in Norway is part of this research-underfunded system and still in many ways struggles to reach a desirable size and quality. So let us have a closer look at the infrastructure and see what has happened.

The healthcare system in Norway is public, with almost all hospitals being owned and funded by the state. Due to a rather decentralized pattern of living, with a large $\left(387000 \mathrm{~km}^{2}\right.$, including Svalbard and Jan Mayen) and long (1752 km from south to north) country and a 'small', stable population (4.6 million; 11.8 inhabitants per $\mathrm{km}^{2}$ ), there has historically been a large number of rather small hospitals and clinics scattered around. The care of psychiatric patients was often organized in separate institutions, apart from the somatic medicine and research-oriented driving forces. Indeed, scientific projects could (up to these days) be viewed as nonproductive expenses, as opposed to the practical clinical work. The four universities are (as expected) present in the major cities Oslo, Bergen, Trondheim and Tromsø, with Stavanger to follow as the next. It has therefore been a major challenge for decades to establish and keep a critical mass of academic positions and resources for research activities, in close contact with the clinical care-giving sites, both at the university departments and in the relevant specialized institutions.

In the beginning of the 1980s, the Research Council of Norway (RCN; www.forskningsradet.no) initiated two 5-year programs in 'Clinical Psychiatric Research' (including child psychiatry) and 'Clinical Psychological Research’. These programs were both continued and subsequently merged in 1990 as a general 'Program for Research on Mental Health'. The initiation was based on the recognition that these fields had scarce activity and lagged far behind international standards, despite some admirable exceptions. According to professor Per Vaglum, who chaired major parts of this process, Norwegian psychiatry was made scientific during this decade, with the creation of a culture of enquiry among the clinicians. The results could be counted as an increase in the number of $\mathrm{PhD}$ dissertations, which was almost the same for the periods 1927-1981 and 1982-1990.

As seen from the outside, some of the strengths of psychiatry-related research in Norway seem to be linked to a structural advantage: we have a rather uniform, stable population and a respected public health system, and people tend to participate in large cohort-based epidemiological surveys. As an example, the Nord-Trøndelag Health Study (HUNT; www.hunt.ntnu.no) is one of the largest health studies ever performed, with a unique database of personal and family medical histories. HUNT-1 was carried out in 1984-86 to establish the health history of 75000 persons, whereas HUNT-2 was performed in 1995-97 to study the evolution of the health history of 74000 persons, including blood sample collection and biobank information from 65000 of the volunteers. Indeed, about $75 \%$ of the population in NordTrøndelag County participated in the HUNT study during its two periods. Hopefully, HUNT-3 will be run with the same success. Another example is the Norwegian Mother and Child Cohort Study, which intends to follow 100000 pregnant women (www.fhi. no). The purpose of this project is to find causes of serious diseases among mothers and their children. The research questions are mainly related to environmental factors, such as medications, nutrition, infections and work exposure, but genetic factors as well as the interplay between genes and the environment are also studied. The Norwegian health surveys and related epidemiological and genetic studies have already proven to be potential gold mines for psychiatric research, as evidenced by articles in the very best international journals. And it is probably more in the pipeline, as exemplified by the recent 
NIH 12 mill USD grant for the collaboration between the Norwegian Mother and Child Cohort Study and researchers at the Columbia University, including the Autism Birth Cohort (ABC) project.

Other strong fields in Norwegian academic psychiatry include several longitudinal multicenterbased clinical studies and multidisciplinary research groups, as well as neurocognition and neuroimaging. The Oslo-Stavanger multicenter collaboration on firstepisode psychosis has produced data of high quality and international recognition. The Bergen Mental Health Research Center is an example of multidisciplinarity, where specialists in several subfields (clinical psychiatry, cognition, neuroimaging, psychiatric genetics, functional genomics, neurochemistry and neurophysiology) have merged their interests to focus on psychotic disorders.

But there are still some more steps to climb. The report 'Medical Research in Norway-Bibliometric Indicators', which was presented in 2003, gave an upto-date description of clinical research including psychiatry. ${ }^{2}$ It had been requested by RCN and was based on data provided by the Institute for Scientific Information (ISI) for the 5-year period 1998-2002, although some trends have been provided since 1981 . Interestingly, the contribution of Norwegian research articles in psychiatry/psychology had gradually improved from around $0.35 \%$ of the annual world production in $1981-83$ to about $0.7 \%$ in 1996 , which in time completely overlapped with the initiation of strategic research programs in clinical psychiatry and psychology (see above). On the negative side, this percentage levelled out at $0.7 \%$ for 1998-2002, amounting to some 140-170 papers per year. Moreover, the calculated relative citation index for Norway in psychiatry/psychology (71\%) shows that these articles are generally cited significantly below the world average of the field, far below the leading countries such as UK, USA and our neighbors Denmark, Finland and Sweden. The main articlecontributing institutions are the Universities of Oslo (39\%) and Bergen (15\%).

To complete the evaluation process, a panel of international experts finished a review of psychiatric and psychological research in Norway by the end of $2003 .^{3}$ Their overall conclusion was that research in this field demonstrated large qualitative differences within each of the two disciplines, spanning from groups 'that maintain front line research in a worldwide perspective' to groups 'that are basically unproductive'. More specifically, a total of 23 departments/groups were reviewed, with the following outcome: 'excellent' or 'very good to excellent' $(n=5 ; 22 \%)$, 'very good' or 'good to very good' $(n=4 ; 18 \%)$, 'good' $(n=7 ; 30 \%)$, and 'fair to good', 'fair', 'fair to weak' or 'weak' $(n=7 ; 30 \%)$. This ranking has several interesting aspects and may be read with an optimistic view for the future, pending proper strategic adjustments. The committee worried about 'an inward looking attitude to research with no or very little interest in what is going on in the international scientific community at large', followed by 'lack of focus' and a need for 'better scientific leadership'. The introvert view is perhaps not surprising for a country that in two separate referendums has turned down membership in the European Union, but the other problems are for sure not specific to Norway and should be relevant to several fields and countries worldwide.

For the years ahead, there are some promising leads for a new rise in academic psychiatry in Norway, based on our present achievements. First, there is a political understanding to focus on the psychiatric healthcare, which hopefully may improve the challenging recruitment situation in clinical psychiatry, with positive spin-off effects on the academic side. Second, new legislation and economical incentives have instructed and 'forced' all hospitals to include research as one of their four main tasks. The funding is substantial, at least in the perspective of Norwegian scientists, and so far, it seems that psychiatric research of high quality is getting its fair proportion of the money. A continuing problem however is that talent recruitment is still a challenge. The salaries are markedly higher in clinical psychiatric work as compared to academic positions. In spite of current limitations, it is a reasonable prediction that the combination of several skilled research leaders, strategic decisions in line with advice from the recent international evaluation and new funding opportunities will bring inspiration, more focus and higher quality and quantity into academic psychiatry in Norway. ISI will give us the answers in due time.

VM Steen

Dr Einar Martens Research Group for Biological Psychiatry, Section for Medical Genetics and Molecular Medicine, Bergen Mental Health Research Center, Haukeland University Hospital, University of Bergen, Norway E-mail: Vidar.Martin.Steen@helse-bergen.no

1 The Norwegian Research and Educational System-Statistics and Indicators. The Research Council of Norway: Oslo, 2003, ISBN 82-12-01881-4. http://forskningsradet.ravn.no/bibliotek/statistikk/ indikator_2003/.

2 Aksnes DW (ed) Medical Research in Norway-Bibliometric Indicators. The Norwegian Institute for Studies in Research and Education (NIFU): Oslo, NIFU skriftserie no. 9/2003, ISSN 0808-4572. www.nifustep.no/norsk/publikasjoner/medical_research_ in_norway_bibliometric_indicators.

3 Evaluation of Clinical, Epidemiological, Public Health, Healthrelated and Psychological Research in Norway. Panel 3, Psychology and Psychiatry. The Research Council of Norway: Oslo, 2004, ISBN 82-12-01894-6. www.forskningsradet.no/CSStorage/Vedlegg/Health3. pdf. 